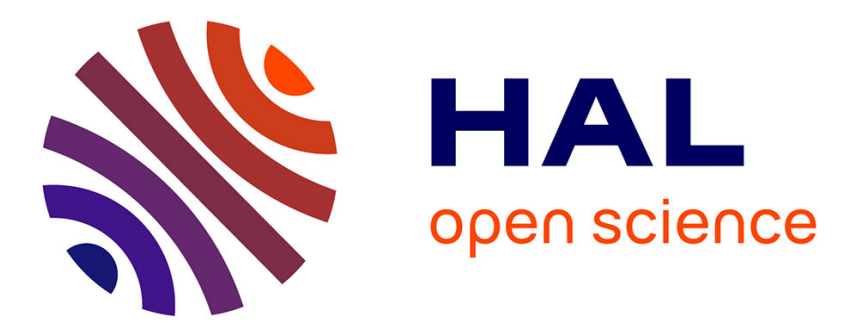

\title{
Effects of personal goal management program on school and football self-determination motivation and satisfaction of newcomers within a football training centre
}

\author{
Raphaël Laurin, Michel Nicolas, Marie-Françoise Lacassagne
}

\section{To cite this version:}

Raphaël Laurin, Michel Nicolas, Marie-Françoise Lacassagne. Effects of personal goal management program on school and football self-determination motivation and satisfaction of newcomers within a football training centre. European Sport Management Quarterly, 2008, 8, pp.83-99. halshs-00490951

\section{HAL Id: halshs-00490951 \\ https://shs.hal.science/halshs-00490951}

Submitted on 17 Jun 2011

HAL is a multi-disciplinary open access archive for the deposit and dissemination of scientific research documents, whether they are published or not. The documents may come from teaching and research institutions in France or abroad, or from public or private research centers.
L'archive ouverte pluridisciplinaire HAL, est destinée au dépôt et à la diffusion de documents scientifiques de niveau recherche, publiés ou non, émanant des établissements d'enseignement et de recherche français ou étrangers, des laboratoires publics ou privés. 
Effects of personal goal management program on school and football selfdetermination motivation and satisfaction of newcomers within a football training centre.

\author{
Raphael Laurin \\ Michel Nicolas \\ Marie-Françoise Lacassagne \\ University of Burgundy \\ Dijon (France)
}

Address for correspondence:

Raphaël LAURIN

School of Sport Sciences and Physical Education

Burgundy University

21078 Dijon cedex

Tel: (33) 0380399013

E-mail : laurin_raphael@yahoo.fr 


\begin{abstract}
The aim of this study was to evaluate the effects of a personal goal-based intervention on school and football self-determination motivation and satisfaction of newcomers within football training centres. Twenty-three trainees were divided randomly into two groups, either a treatment group or a control group. The treatment proposed to the participants was the personal goal management program (Bouffard, Labelle, Dubé \& Lapierre, 1999). Trainees' school and football motivation and satisfaction were measured before, during and after the intervention. Results indicated a beneficial influence on football motivation and satisfaction, and overall trainee satisfaction. Methodological and applied suggestions are made to favour adjustment of newcomers within football training centre.
\end{abstract}

Key words: personal goal, motivation, satisfaction, football training centre, newcomers. 
Effects of a personal goal management program on the school and football self-determination motivation and satisfaction of newcomers within a football training centre.

In the context of French football, each professional club manages a centre in charge of the training of young talented players with potential to perform at the highest national level. These centres aspire to develop players for the first team or to generate income through their sale to other clubs. In France, these football training centres recruit players aged between 14 and 16, based on sporting criteria and offer school education together with football training for three to four years. Generally, before joining these football training centres, players have developed skills and abilities in a club (either where the centre is based or elsewhere) or in a federal pre-training centre. Although various organizational differences exist in these centres (within France and throughout other countries), the norm is for trainees to board, that is they live within the centre and their everyday life is punctuated by the alternation between school education and training for football. This environment is completely new for these trainees. It involves changes in social, school and football domains, to which each of them must adjust. At the social level, each must adapt to new rules of life specific to this community, and they must also move towards a relational disengagement with their parents and an investment with the other actors of the centre, especially their peers and their coaches. Moreover, the scholastic conditions differ from those found in 'normal' educational institutions. There is less learning time, and the size of the learning group is reduced. The challenge for these trainees is to maintain a level of motivation towards their schooling, which is sufficient to assure their progress in the curriculum (Richardson, Gilbourne \& Littlewood, 2004). Indeed, in terms of 
their football development, the trainees are involved in an intensive technical, tactical, physical, and psychological training program. Their entry into this system sensitizes them to questions of professionalism (Richardson et al., 2004). They move in a highly competitive world, in which there is no guarantee of continuing their training at the end of the season (or year). As suggested by Brettschneider (1999), the most significant difficulties for this population relate to uncertainty concerning their sporting future and the necessity for them to manage the double demands of school and football. So, one of the stakes for these young sportsmen and for the centres is the mobilization of psychological skills to allow them to adjust to these changes (Danish, Petitpas \& Hale, 1993). In some European countries, particularly in France since a decree of July $18^{\text {th }}, 2002$ psychological support for sportsmen and women participating in high level sports training programs has been reinforced. In this study, the authors sought to test the effects of a psychological intervention on the adjustment of newcomers in football training centre.

Richardson et al. (2004), stress the growing importance of developing psychological support to foster trainees' adjustment. According to self-determination theory, a behavior is adjusted if it satisfies fundamental psychological needs such as autonomy and feelings of competence (Deci \& Ryan, 1985, 2000). Social contexts and psychological dispositions which help in the realization of these needs, tend to be intrinsically motivated behavior, that is to say where behaviour represents something which is intrinsically valued (Deci \& Ryan, 1985, 2000). Various studies revealed that intrinsic motivation is associated with stronger persistence, performance or satisfaction (Baard, Deci \& Ryan 2005; Fortier, Vallerand \& Guay, 1995; Rousseau \& Vallerand, 2000). Researchers' interest in factors that promote adjustment have already demonstrated the importance of pursuing personal goals (Deci \& Ryan, 2000). In sports settings, previous research has tested the effects of the Goal Setting techniques on athletes' physical performances, without showing consistent effects (Hall \& 
Kerr, 2001; Weinberg \& Weigand, 1993). In this study it is assumed that trainees' adjustment will be supported by their participation in a personal goals management program (PGMP). Goal Setting and the PGMP adopt the same theoretical assumption, that goals are the most immediate and the most direct regulators of human action (Locke \& Latham, 1990). Nevertheless, there is an essential distinction between these two techniques. Goal Setting is a technique used to improve the performance and persistence of an individual (Famose, Sarrazin \& Cury, 1999). Generally, goals are assigned at the time of a discussion and must be accepted by the athlete. In the PGMP, the framework of intervention aims to promote the emergence of selected goals in an autonomous way, having an intrinsic value for the individual. A key distinction then is that the PGMP, rather than the Goal Setting approach, promotes the identification of intrinsically oriented goals. Moreover, the PGMP, unlike Goal Setting, requires consideration and articulation of goals in relation to all the athlete's activities because it is an initiative centred on the person. In relation to this population which is the concern of this paper, it also offers an approach which lends itself to the reconciliation of education and football goals. Finally the PGMP distinguishes various phases of goal realization and proposes a frame facilitating the trainees' involvement at each stage, and this lends itself particularly to work with such a young population.

The PGMP approach is constructed on identified steps in the development of personal goals: elaboration, planning, pursuit, and evaluation (Golltwitzer, 1993; Nuttin, 1985). The elaboration of goals is necessarily carried out in a social context (Cantor, 1990) and is based on psychological needs (Nuttin, 1985). During this step participants are invited to draw-up an inventory of their aspirations, to clarify them, to select their priorities, to formulate precise behaviours, and to begin to carry them out. The planning is a psychological exercise which prepares action (Tubbs \& Ekeberg, 1991). Different strategies are mobilized through the exploration of possibilities, the search for means, the specification of stages, the identification 
of necessary skills, and the prediction of difficulties (Cantor \& Fleeson, 1994). During the intervention, participants are invited to plan in detailed way actions to carry out and to anticipate the obstacles and the strategies to fulfil their goals. The two first steps represent the time required to set goals, before their actualization, and thus involve acts oriented towards elaborated goals, and their evaluation, which refers to a kind of final evaluation focused on the realization of goals. Previous studies on students (Bouffard, Bastin, Lapierre \& Dubé, 2001) and retired (Dubé, Lapierre, Bouffard \& Labelle, 2000) populations, have suggested that the PGMP has had a beneficial influence on adjustment indicators such as Diener's life satisfaction scale (1985) and Smith and Robbins‘s goals orientation scale (1988).

As Bouffard et al. (2001) suggest, the PGMP can also be applied to different age groups and to other contexts, such as that of new trainees in football training centres. In this research, the authors anticipated that the trainees' participation in the PGMP would favour their self-determination in relation to both schooling and football. According to Vallerand and Losier (1999), it is postulated that the highest level of self-determination is inherent in intrinsic motivation. More precisely, an effect on trainees intrinsic motivation to achievement was expected, where intrinsic motivation was considered as an involvement process in an activity for the pleasure of surpassing oneself, of feeling competent, or of reaching personal goals (Vallerand \& Losier, 1999). Moreover, the authors hypothesized that participation in the PGMP would promote trainees' satisfaction and more specifically satisfaction in relation to both school and football.

Method

\section{Participants}

Twenty-three French participants took part in this study (Age: $M=15.9, \mathrm{SD}=1.1)$. All were male and trainees at the same football training centre. They all belonged to the group of players taking part in the national championship in their age category. Only four of them were 
not newcomers: and these four had one year of experience in the centre. Participants were invited to take part in one of the two interventions proposed: the 'treatment' or the neutral task. Five declined to participate. Subsequently the 23 participants were randomly allocated to two groups: a treatment group of 13 trainees (Mean age $=15.9, S D=1.2$ ) and a control group of 10 trainees (Mean age $=15.8, S D=0.9)]$. All consented to participate until the end of the study.

\section{Measures}

\section{Sport motivation scale}

The French version of the Sport Motivation Scale (SMS), developed by Brière, Vallerand, Blais and Pelletier (1995), was used to evaluate trainees' motivation for football. The SMS is a 28-item measure of motivation based on the theoretical model of motivation of Deci and Ryan (1985). The scale has seven sub-scales assessing three types of extrinsic motivation (external (EMER), introjected (EMIN) and identified (EMID) regulation), three types of intrinsic motivation (motivation to know (IMTK), to accomplish things (IMTA) and to experience stimulation (IMES)) and amotivation (AMOT). Respondents were asked to rate each item on a seven-point scale $(1=$ does not correspond at all, $7=$ corresponds exactly $)$ which related to the reasons why they play football. For each sub-scale and for each measure, the internal consistency (Cronbach alpha) was superior to .75. The self determination index was calculated following this formula: $2 *((\mathrm{IMTK}+\mathrm{IMTA}+\mathrm{IMES}) / 3)+($ EMID $)-((\mathrm{EMIN}+$ EMER)/2) - 2*AMOT. This weighting procedure forms a continuous variable from less (below zero) to more (higher than zero) self-determination in the sport context. Thus, scores could vary from -18 to +18 . Previous, research has demonstrated the reliability and the validity of this index (Guay \& Vallerand, 1997; Vallerand, Fortier \& Guay, 1997). 
The French version of the Academic Motivation Scale (AMS), developed by Vallerand, Blais, Brière and Pelletier (1989), was used to evaluate trainees' motivation for school. Like the SMS, the AMS is also a 28 -item measure of motivation, based on Deci and Ryan's (1985) theoretical model of motivation. This scale has seven sub-scales assessing three types of extrinsic and intrinsic motivation and amotivation. For each sub-scales and for each measure, the internal consistency (Cronbach alpha) was superior to .70. Respondents were asked to rate each item on a seven-point scale to the extent to which it corresponds to the reasons they go to school. As for the SMS, the self determination index was calculated. Scores could vary from -18 to +18 .

\section{Satisfaction}

In order to measure the satisfaction of their experiences within the centre, we used the Football Trainee Adjustment Scale (STAS) (Laurin, 2007). This scale was adapted from the "Institutional Integration Scale" (Pascarella \& Terenzini, 1980), developed in the educational context from Tinto's model (1975). The STAS is a 13-item measure of satisfaction. Participants were asked to indicate their level of agreement with each of the statements. Responses were obtained on a five-point scale, anchored at the extremes by "strongly disagree" and "strongly agree". Five subscales assessed peer adjustment ("Within the centre, I have no difficulties in making friends with other trainees."; "I think my relations with other trainees are satisfying."), supervisor adjustment ("My relationship with the supervisor(s) is satisfying."; "I am satisfied with the interest the supervisor(s) show(s) towards the trainees."), football adjustment ("I am satisfied with the training proposed within the training centre."; "I am satisfied with my relationship with my coach.”), school adjustment ("I am satisfied with the lessons given within the centre."; "I am satisfied with the interest shown by the teachers towards the trainees.") and board adjustment ("I respect the centre's rules."; "I think I behave well in this centre.”). For each sub-scales and for each measures, the internal consistency 
(Cronbach alpha) was superior to .73. The trainees' satisfaction corresponds to the average scores of each subscale. For each measure the internal consistency (Cronbach alpha) of the 13 items was superior to .82 . The football and school satisfaction subscales and the average scores of each subscale, the overall trainee satisfaction, were measured.

\section{Social validity}

Social validity addresses three fundamental questions of intervention design: what should be changed?; how should be it changed?; and how will we know the intervention was effective? (Gresham \& Lopez, 1996). These questions suppose the assessment of the social significance of the intervention goals, the social acceptability of the components of the intervention to reach the goals and the evaluation of the social importance of the effects resulting from the intervention (Kazdin, 1977; Van Houten, 1979; Wolf, 1978).

In this study three items were proposed to evaluate the social validity of intervention:

1) "I think the goal pursued by this intervention was important for me".

2) "I think the way this intervention was carried out was satisfactory".

3) "I think this intervention helped me, particularly regarding school and football activities".

Respondents were asked to evaluate each item on a five-point scale to the extent to which it describes the way they think. This evaluation was anonymous. Questionnaires were indirectly returned (via the supervisor) to the speaker.

\section{Procedure}

In agreement with the football training centre, interventions and evaluations started at the beginning of the sport season (which lasts from September to June). The participants were gathered with the first author and their trainer at the start of the study and it was explained that the study aim was to evaluate the effects of specific intervention techniques (individual and group). The participants were asked to not discuss the nature of the study in any way with other participants of the study. They were then randomized into groups without knowing the 
experimental or control nature of the group they belonged to. For ethical reasons, at the end of the intervention it was proposed, in agreement with the staff, that the control group should follow the PGMP, the following season. Unfortunately, as often occurs in the football context, the leaving of key staff members did not allow this intervention to be pursued. A pre- and post-intervention measure was made for satisfaction and motivation variables. One and three intermediary measures were made respectively for motivation (T3) and satisfaction (T2, T3 and T4) variables. All the trainees were asked to respond at the same time, when they were gathered in the same room. All interventions took place within the training centre, with the same interviewer. The intervention and evaluation times are detailed in the Figure 1.

\section{Treatment}

The content of the treatment was an adaptation of the PGMP (Bouffard et al., 1999). The program developed by Bouffard et al. (1999) with students is a psycho-pedagogical approach aiming particularly at the learning of the process of elaboration and realization of a project. It is applied over a short period ( 11 weeks) and through work in small groups ( 3 or 4 students). These conditions did not seem appropriate for our population for several reasons. First, small working groups seemed difficult to set up given the competitive dynamic between the trainees especially, in the football context. Second, in this specific environment it seemed to the authors more relevant to propose a process of 'accompaniment' throughout the season and to propose individual interviews of clinical type as a vehicle rather than work in small groups. So, the framework used was an eight-month intervention, including a preliminary group interview and five one-hour face to face individual interviews, which took place in a room within the training centre. These features apart, the structure of the PGMP was respected, the program framework of preliminary, elaboration, planning, pursuit and evaluation phases of the personal goals. The program began six weeks after the trainees' entry, in order to allow 
them to experience the constraints and the opportunities of the centre. Sufficient time was required to allow them to develop and plan coherent personal objectives.

During the preliminary group interview trainees were asked to prepare the first individual interview thinking of their motivation for joining a football training centre. Each individual interview was semi-directive, during which the interviewer used a guide. They were considered semi-directive because the interviewer made sure that the trainees verbalization mainly focused on school and football activities. As for the guide, it allowed the interviewer to keep a written track of the oral responses in order to keep a consistent record. During the elaboration and planning stage, the trainees' speech was orientated towards opportunities and constraints linked to the environment and on the perception of their personal skills (knowledge, know-how, and behaviour) in football and school contexts. The interviewer encouraged trainees to clarify their goals and the definition of means to achieve them. During the pursuit stage, trainees were prompted to reformulate each goal and to evaluate how these had developed, then to analyze them and finally to make a decision (Table 1).

The framework used individual interviews of a clinical type, repeated in order to illustrate the participants' development. This type of interview was chosen because it is technically the best for accessing to subjective information (representation, mood, motivation, experience) testifying to the singularity and the complexity of a subject (Chiland, 1989). The interviewer informed each trainee of the interview conditions and of the possibility of withdrawing from the program if they wished. Trainees were informed of the goals of the program: i.e. to elaborate, plan and achieve their personal goals; of the type of relation between the speaker and the trainee: i.e. a collaboration; on the duration of collaboration: i.e. five individual interviews over a period of seven months; and on the method: i.e. to propose a space-time context in which they could " speak of their life in the centre, of what they wanted to do in the centre and of the means to achieve their goals». The fundamental principles of the 
individual clinical type interviews were respected: confidentiality, benevolence, neutrality and empathy. These principles are in line with the Rogerian approach to the clinical interview (Rogers, 1942) and favour the creation of a confidence climate between the participant and the speaker. These principles favour also the capacity of the speaker to speak freely and the capacity of the interviewer at the same moment to understand, by identification, what lives the speaker and to communicate what he understands. In addition, it increases both awareness and acceptance of negative mood and acceptance of negative mood is hypothesized to develop more effective coping skills, diminishing the sense of uncontrollability.

During the elaboration and the plan, verbal interventions such as reformulation, questioning and reiteration, supporting the expression and clarification of goals were used. To facilitate the development of strategies allowing realization of goals, the interviewer used a problemsolving technique. This aimed at supporting the trainees' analytical stage and decisionmaking. During all the treatment, support and counselling strategies were used to help trainees to cope with difficulties. The interviewer could promote revaluation of the goal or of means to achieve it.

\section{Neutral task}

The trainees of the control group participated in five group meetings during the intervention period. These meetings lasted approximately one hour. The goal was to propose to them a time to discuss and analyze the quality of their collective and individual performances. Each one was invited to give his opinion on the quality of the performance of his team, his adversary, and on the quality of his own performance. The interviewer's role was to regulate each trainee's time of speech. Nobody talked about football or school-related goals during these sessions.

Data Analysis 
The effect's size was calculated for each variable by applying the procedure suggested by Cohen (1988). This index allows to evaluate the effects independently of the sample size. This procedure was used to evaluate the within and the between group differences. Cohen (1988) defined effect size as "small" $(d=.2)$,"medium" $(d=.5)$ and "large" $(d=.8)$. Repeated measures of variance analysis, with Bonferroni correction, were conducted in which satisfaction and motivation scales were dependent measures, time was a repeated-measure independent variable and a between-group independent variable with two groups, treatment group and control group. Concerning the social validity of the PGMP, we carried out comparative tests between the mean scores of the group of each item (and the mean score on all items) and the reference value $(\mathrm{M}=3)^{1}$.

Results

We hypothesised that between the pre- and post-tests, the level of football and school self-determination and satisfaction and the trainees satisfaction would increase in the treatment group. Moreover, we hypothesized that the evolution between the pre- and posttests of the difference between the two groups regarding the football and school levels of selfdetermination and satisfaction and the trainees satisfaction states would be in favor of the treatment group.

Effect size estimates for the within group differences revealed for the football selfdetermination (F.S.D.) measure a moderate decrease of their expression level in the treatment group and a very strong decrease in the control group. For football intrinsic motivation to accomplish (F.I.M.A.), football satisfaction (F.S.) and trainee satisfaction (T.S.) measures effect size estimates revealed a stability of their expression level in the treatment group and a strong decrease in the control group. Contrary to our expectations effect size estimates for the within group differences revealed for intrinsic school motivation to accomplish (Sc.I.M.A.) and school satisfaction (Sc.S.) measures, the same changes were evident in the two groups 
respectively a moderate increase and a strong decrease. Moreover, the school selfdetermination (Sc.S.D) expression level had strongly decreased in the treatment and weakly increased in the control group. Furthermore, effect size estimates for the between group differences showed that the expression level of F.S.D, F.I.M.A., F.S. and T.S. in pre-test for the treatment group was lower for the control group even though in post-test this was higher. This was not the case for the school variables. Results are presented in Tables 2 and 3.

A significant group* time effect in favor of the treatment group was identified for football self-determination motivation, $F(2,44)=3.94, p=.02)$, for football intrinsic motivation to accomplish, $F(2,44)=6.98, p=.008)$, for football satisfaction, $F(4,88)=2.61$, $p=.035)$ and trainee satisfaction, $F(4,88)=2.83, p=.015)$. With a limit of acceptance fixed at $p<.012$ for motivation variables $(.05 / 4$ variables $)$ and $\mathrm{p}<.016$ for satisfaction variables $(.05 /$ 3 variables), the effect was still significant for the variables of football intrinsic motivation to accomplish and trainee satisfaction.

Concerning the social validity of the PGMP, a t-test revealed a significant differences between the reference value $(\mathrm{M}=3)$ and the mean score of the item $1(\mathrm{M}=3.58)$ and $2(\mathrm{M}=$ 4.33) and the mean score of the three items $(\mathrm{M}=3.64)($ Table 4).

\section{Discussion}

The aim of this study was to evaluate the effects of the new football training centre trainees' participation in the PGMP on school and football motivation and on trainee satisfaction and more specifically the satisfaction with school and football.

Football self-determination remained stable all along the season for the trainees taking part in the PGMP whereas it decreased substantially for the control group. Moreover, this intervention enabled the stabilization of the level of intrinsic motivation to accomplish in football of the treatment group whereas for the control group's this measure steadily decreased. Some studies on sport and student populations have shown that the more an 
individual's social context upholds his autonomy, the more s/he perceives himself/herself as autonomous and competent, and the more his/her school and sport self-determination is high (Vallerand \& Losier, 1999; Vallerand, Fortier \& Guay, 1997). So we might assume that the context created by this program favored the feeling of autonomy and competence for trainees, and thus the intrinsic nature of the football motivation.

Nevertheless, PGMP did not influence trainees' school motivation. Contrary to our expectations, the school self-determination and the school intrinsic motivation to accomplish of the two groups did not evolve differently during the season. Moreover, the school satisfaction of the treatment group did not evolve differently from that of the control group. These results are corroborated by the numerous studies expressing a positive relationship between intrinsic motivation and individual satisfaction (Baard, Deci \& Ryan, 2005; Baker, 2004; Walls \& Little, 2005). Finally, we note that the school self-determination level of trainees was largely lower than that for football self-determination. Indeed, the trainees felt less involved in their school activities. During the interviews, we noticed a lack of spontaneous interest and a low personal involvement regarding the school context. As suggested by Parker (2000), in spite of the introduction of educational training programs to offer players some kind of safeguard against the high probability of occupational failure, the cultures within the centres does not value the pursuit of the educational program but by contrast glorifies sporting success. On the other hand, the football satisfaction of the treatment group remained stable, unlike that of the control group decreased. We can explain this by the dependence between the self-determination level towards an activity and the satisfaction that it provides. Moreover, we noticed a significantly different evolution between the trainee satisfaction levels of the two groups: stable for the treatment group and decreasing for the control group. Although no statistical treatment was used in this study to evaluate it, this result upholds the "spillover hypothesis". This hypothesis holds that there are bidirectional 
influences between specific and global satisfaction (Rain, Lane \& Steiner, 1991). One potential moderator of this relationship is the perceived importance or value relevance of a given life domain for a particular individual (Lent, 2004; Oishi, Diener, Lucas \& Suh, 1999).

Globally, PGMP has not increased the football motivation and satisfaction levels of the treatment group. The competitive context proposed by a training centre may explain this phenomenon. Indeed, any trainee can be dropped from the centre if his football performances are not good enough. Yet, studies to date have shown, an evaluation situation favours a decrease of intrinsic motivation and satisfaction (Amabile, DeJong \& Lepper, 1976 ; Amabile, Goldfarb \& Brackfield, 1990 ; Grolnick \& Ryan, 1987).

Nevertheless, theses quantitative results support a beneficial influence of the PGMP on the trainees, confirmed by their evaluation of this program. Indeed, the trainees considered that the goal of the PGMP, to favor elaboration and achievement of their personal goals, was important for them. Moreover, they expressed satisfaction towards the method used. On the other hand, we noticed that they evaluated less positively the help offered by this program towards both school and sport activities. On this point, the high level of interindividual variance of the group $(\mathrm{M}=3.01, \mathrm{SD}=1.08)$ conveys the necessity of a process of subjective evaluation of the intervention to illuminate interindividual differences in order to qualify the conclusions on its effects.

Indeed, one limit of this study concerns the absence of control of the participants' personal psychological characteristics, particularly some personality factors such as neuroticism. This trend of an individual to experience fear, sadness or disgust (Costa \& MaCrae, 1992) is a phenomenon which is strongly linked to well-being (Judge, Erez, Bono \& Thoresen, 2002), particularly during a transitional period of life (Kling, Ryff, Love \& Essex, 2003). Moreover, some studies have recently revealed that the more a person shows a high level of conscientiousness, the more important and stable the level of self-determination is 
(Ingledew, Markland \& Sheppard, 2004; Judge \& Ilies, 2002). The second limit is methodological. It concerns the small size of the sample which warrants precaution when interpreting the results, and the control of contextual variables. In future studies it will be important to control the playing time average of each trainee. This is a criterion of achievement for a football player, likely to influence how competent he feels (Williams \& Reilly, 2000).

On the other hand, in an interventionist perspective, this research presents several important findings. It has shown some support for the PGMP as a vehicle to moderate adjustment difficulties faced by the newcomers in a football training centre. The framework proposed in the PGMP is different from those usually proposed in sport, such as Goal Setting of cognitive-behavioural orientation (Locke \& Latham, 1985) or the ego-reconstruction of psychoanalytical orientation (Carrier, 1993; Hanna, 1993). The PGMP overcomes the specific, unidimensional and especially more or less ascribed aspect of elaborated goals as regards goal setting, making it a personal and a more comprehensive process. It also enables practitioners to go further than simply a fostering of the emergence of personal desires by giving concrete means to achieve goals. Moreover, this work offers a new research perspective for a question of increasingly recognised importance. It highlights the interest to propose conditions favoring the football and school's feeling of autonomy for this specialist population. To increase this feeling, future studies could focus on the elaboration and the evaluation of a program working also on the motivational climate created by the teachers, coaches and supervisors. 


\section{References}

Amabile, T.M., DeJong, W. \& Lepper, M.R. (1976). Effects of externally imposed deadlines on subsequent intrinsic motivation. Journal of Personality and Social Psychology, 34, 9298.

Amabile, T.M., Goldfarb, P. \& Brackfield, S.C. (1990). Social influences on creativity: evaluation, coaction and surveillance. Creativity Research Journal, 3, 6-21.

Baard, P.P., Deci, E.L. \& Ryan, R.M. (2005). Intrinsic need motivation: A motivational basis of performance and well being in two work setting. Journal of Applied Social Psychology, 34, 2045-2068.

Baker, S. R. (2004). A prospective longitudinal investigation of social problem-solving appraisals on adjustment to university, stress, health and academic motivation and performance. Personality and Individual Differences, 35, 569-591.

Bouffard, L., Labelle, R., Dubé, M. \& Lapierre, S. (1999). La gestion des buts personnels Programme d'intervention visant l'amélioration du bien-être psychologique. Université du Québec à Trois-Rivières.

Bouffard, L., Bastin, E., Lapierre, S. \& Dubé, M., (2001). La gestion des buts personnels, un apprentissage significatif pour des étudiants universitaires. Revue des Sciences de l'Education, 27, 503-522.

Brettschneider, W.D. (1999). Risks and opportunities: adolescents in top level sport - growing up with the pressures of school and training. European Physical Education Review, 5, 121133.

Brière, N.M., Vallerand, R.J., Blais, M.R. \& Pelletier, L.G. (1995). Development and validation of an intrinsic, extrinsic and amotivation scale in sport contexts. International Journal of Sport Psychology, 26, 465-489. 
Cantor, N. \& Fleeson, W. (1994). Social intelligence and intelligent goal pursuit: a cognitive slice of motivation. In W.D. Spaulding (Ed.); Integrative views of motivation, cognition and emotion (p.125-179). Lincoln: University of Nebraska Press.

Carrier, C. (1993). Les risques identitaires de l'adolescent champion. Editions I.N.S.E.P. Paris.

Chiland, C. (1989). L'entretien clinique. Paris : PUF.

Cohen, J. (1988). Statistical power analysis for the behavioral sciences (2nd ed.). Hillsdale NJ: Lawrence Earlbaum Associates.

Costa P. T. \& McCrae R. R. (1992). Normal personality assessment in clinical practice: the NEO Personality Inventory. Psychological Assessment, 4, 5-13.

Danish, S.J., Petitpas, A.J. \& Hale, B.D. (1993). Life development intervention for athletes: Life skills through sports. The Counseling Psychologist, 21, 352-385.

Deci, E.L. \& Ryan, R.M. (1985). Intrinsic motivation and self-determination in human behavior. New York: Plenum.

Deci, E.L. \& Ryan, R.M. (2000). The "what" and "why" of goals pursuits: human needs and the self-determination. Psychology Inquiry, 11, 227-268.

Diener, E., Emmons, R.A., Larsen, R.J. \& Griffin, S. (1985). The satisfaction with life scale. Journal of Personality Assessment, 49, 71-76.

Dube, M., Lapierre, S., Bouffard, L. \& Labelle, R., (2000). Le bien être psychologique par la gestion des buts personnels: une intervention de groupe auprès de retraités. Revue Québécoise de Psychologie, 21, 255-280.

Famose, J.P., Sarrazin, P. \& Cury, F. (1999). La fixation de but: une technique pour surmonter l'anxiété et augmenter la confiance en soi, In C. Le Scanff \& J.P. Famose, $\quad L a$ gestion du stress, entraînement et compétition (pp. 26-46), Paris, Edition Revue EPS. 
Fortier, M.S., Vallerand, R.J. \& Guay F. (1995). Academic motivation and school performance: Toward a structural model. Contemporary Educational Psychology, 20, 257274.

Gollwitzer, P. (1993). Goal achievement: the role of intentions. In M. Hewstone \& Stroebe (Eds), European review of social psychology (vol. 4, p. 141-185). Chichester: Wiley.

Gresham, F.M. \& Lopez, M.F. (1996). Social validation: A unifying construct for school based-consultation research and practice. School Psychology Quarterly, 11, 204-227.

Grolnick, W.S. \& Ryan, R.M. (1987). Autonomy in children's learning: an experimental and individual difference investigation. Journal of Personality and Social Psychology, 52, 890898.

Guay, F., \& Vallerand, R. J. (1997). Social context, students' motivation, and academic achievement: Toward a process model. Social Psychology of Education, 1, 211-233. Hall, H. \& Kerr, A. (2001). Goal Setting in sport and physical activity: tracing empirical developments and establishing conceptual direction. In R. Glyn (Eds), Advances in Motivation in Sport and Exercise (pp. 183-233), Champaign, USA, Human Kinetics Publishers.

Hanna, E.A. (1993). The psychodynamicaly oriented clinical social worker as sport consultant: A premilary report. Clinical Social Work Journal, 21, 283-300.

Ingledew D. K., Markland D. \& Sheppard K. E. (2004). Personality and self-determination of exercise behaviour. Personality and Individual Differences, 36, 1921-1932.

Judge, T.A. \& Ilies, R. (2002). Relationship of personality to performance motivation: a metaanalytic review. Journal of Applied Psychology, 87, 797-807.

Judge, T.A., Erez, A., Bono, J.E. \& Thoresen, C.J. (2002). Are measures of self-esteem, neuroticism, locus of control and generalized self-efficacy indicators of a common core construct? Journal of Personality and Social Psychology, 83, 693-710. 
Kazdin, A.E. (1977). Assessing the clinical or applied importance of behavior change through social validation. Behavior Modification, 1, 427-452.

Kling K. C., Ryff C. D., Love G. \& Essex M. (2003). Exploring the influence of personality on depressive symptoms and self-esteem across a significant life transition. Journal of Personality and Social Psychology, 85, 922-932.

Laurin, R. (2007). A self-report measure of the adjustment of soccer training center teenagers: the Soccer Trainee Adjustment Scale (STAS). Doctoral thesis, University of Burgundy

Lent, R.W. (2004). Toward a unifying theoretical and practical perspective on well-being and psychosocial adjustment. Journal of Counseling Psychology, 51, 482-509.

Locke E. \& Latham G. (1990). A theory of goal setting and task performance, Englewood Cliffs, NJ: Prentice Hall.

Locke E. \& Latham G. (1985). The application of goal setting to sports. Journal of Sport Psychology, 7, 205-222.

Nuttin, J.R. (1985). Théorie de la motivation humaine. Paris: P.U.F..

Oishi, S., Diener, E., Lucas, R.E. \& Suh, E. (1999). Cross-cultural variations in predictors of life satisfaction: Perspectives from needs and values. Personality and Social Psychology Bulletin, 25, 980-990.

Parker, A. (2000). Training for "Glory", Schooling for "Failure": English professional football, traineeship and educational provision. Journal of Educational and Work, 13, 6176.

Pascarella, E.T. \& Terenzini, P.T. (1980). Predicting freshman persistence and voluntary dropout decisions from a theoretical model. The Journal of Higher Education, 51, 60- 74. 
Rain, J.S., Lane, I.N. \& Steiner, D.D. (1991). A current look at the job satisfaction/life satisfaction relationship: Review and future considerations. Human Resources, 44, $287-$ 307.

Richardson, D., Gilbourne, D. \& Littlewood, M. (2004). Developing support mechanisms for elite young player in a professional soccer academy: Creative reflections in action research. European Sport Management Quarterly, 4, 195-214.

Rogers, C. (1942). La relation d'aide et la psychothérapie. Paris, ESF.

Rousseau, F.L. \& Vallerand, R.J. (2000). Does motivation mediate influence of social factors on educational consequences? Psychological Reports, 87, 812-814.

Smith, L.C. \& Robbins, S.B. (1988). Validity of the goal instability scale (modified) as a predictors of adjustment in retirement-age adults. Journal of Counseling Psychology, 33, 325-329.

Tinto, V. (1975). Dropout from higher education: A theoretical synthesis of recent research. Review of Educational Research, 45, 89-122.

Tubbs, M.E. \& Ekeberg, S.E. (1991). The role of intentions in work motivation: implications for goal-setting theory and research. Academy of Management Review, 16, 180-199.

Van Houten, R. (1979). Social validation: The evolution of standards of competency for target behaviors. Journal of Applied Behavior Analysis, 12, 581-591.

Vallerand, R.J., Blais, M.R., Brière, N.M. \& Pelletier, L.G. (1989). Construction et validation de l'Echelle de Motivation en Education (EME). Canadian Journal of Behavioral Sciences, 21, 323-349.

Vallerand, R.J., Fortier, M.S. \& Guay, F. (1997). Self-determination and persistence in a reallife setting: toward a motivational model of high school dropout. Journal of Personality and Social Psychology, 72, 1161-1176. 
Vallerand, R.J. \& Losier, G.F. (1999). An integrative analysis of intrinsic and extrinsic motivation in sport. Journal of Applied Sport Psychology, 11, 142-169.

Walls, T.A. \& Little, T.D. (2005). Relations among personal agency, motivation and school adjustment in early adolescence. Journal of Educational Psychology, 97, 23-31.

Weinberg R. \& Weigand D. (1993). Goal setting in sport and exercise: A reaction to Locke, Journal of Sport and Exercise Psychology, 15, 88-96.

Williams, A.M. \& Reilly, T. (2000). Talent identification and development in soccer. Journal of Sports Sciences, 18, 657-667.

Wolf, M.M. (1978). Social validity: The case for subjective measurement or how applied behavior analysis is finding its heart. Journal of Applied Behavior Analysis, 11, 203- 214. 


\section{Author's Note}

I the undersigned, Raphael Laurin, attest that the material in the article entitled "Effects of personal goal management on motivation and satisfaction of newcomers within a football training center " has not been previously published and that it is not subject for publication in another review.

Dijon, 20/03/07 


\section{Footnotes}

${ }^{1} 3$ represents the mean score on 5-point Likert scale ranging from 1 to 5 with beyond which the participant represents a more or less strong acceptance of the contents expressed by the item. 


\section{Table 1}

Personal Goal Management Program: objectives and contents of interviews (according to

“the book of personal goal management” by Bouffard, Labelle, Dubé \& Lapierre, 1999).
Stages
Interviews Objectives
Main thematic contents

\begin{tabular}{|c|c|c|}
\hline & & \multirow[b]{2}{*}{ why), the different means by which to materialize } \\
\hline & & \\
\hline & 1 & them as well as the difficulties likely to be met (the \\
\hline planning & Individual & how). \\
\hline of the & & - To foster the planning: means, anticipated obstacles, \\
\hline goals & & strategies to be used, time to be devoted... \\
\hline & & - To set up a moral commitment/ 'contract' to pursue \\
\hline & & theses goals. \\
\hline
\end{tabular}

- To present the objectives and the carrying out of the

Preliminary Group intervention

- To promote debate on their motivation for joining a football training center.

- To promote the definition of goals in the school and sports contexts (the what), what motivates them (the - To articulate the evolution of the degree of realization of their goals.

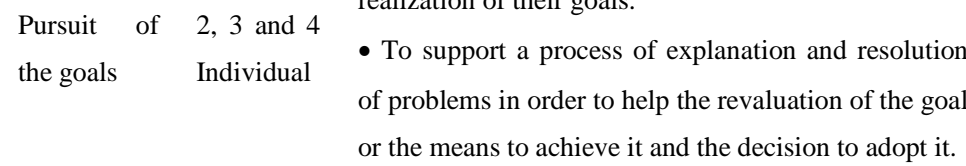

- To assess the degree of realization of, or changes in $\begin{array}{ll}\text { Evaluation } & \\ \text { of the } & 5 \\ \text { program } & \text { Individual }\end{array}$ their personal goals

- To assess the process itself

- To assess the intervention and preparation of the post-intervention (reminder of the goals to be reached and of the process to be used).
- Evoking of their doubts about their level of practice, about their abilities to manage school and football, to live in the boarding context of the center.

- Evoking of their personal skills and limits in the fields of school and sports (knowledge and technical, tactical and physical know-how and social behavior).

- Evoking of opportunities and restraints offered by the training center (material conditions, the role of the coach, the peers and the supervisors)

- Expression of difficulties in managing time and

- To become a professional player

- To experience high level football

- To play football full- time applying the defined strategies

- Accentuation of the importance of sports goals in relation to school ones

- Accentuation of their sensitivity to the coach's feedback.

- Evoking mainly of the degree of realization of their sports goals

- Pursuit of practical advice about the preparation for their school exams

- Evoking of their personal opinion about the intervention. 
Table 2

\section{Means and standard deviations of motivation variables}

\begin{tabular}{|c|c|c|c|c|}
\hline Groups/Variables & $\mathrm{T} 0$ & $\mathrm{~T} 3$ & $\mathrm{~T} 6$ & \\
\hline F.S.D & & & & E.S. (Intra) \\
\hline T.G. & $9.39(1.65)$ & $8.68(1.59)$ & 8.35 (1.74) & -0.61 \\
\hline C.G. & $9.92(1.82)$ & 8.64 (1.73) & $6.97(1.92)$ & -1.57 \\
\hline E. S. (Inter) & -0.31 & & 0.75 & \\
\hline Sc.S.D & & & & E.S. (Intra) \\
\hline T.G. & $2.37(1.14)$ & $1.87(118)$ & $1.32(1.12)$ & -0.92 \\
\hline C.G. & $1.48(1.19)$ & $2.17(1.22)$ & $1.83(1.23)$ & .29 \\
\hline E. S. (Inter) & 0.76 & & -0.43 & \\
\hline F.I.M.A. & & & & E.S. (Intra) \\
\hline T.G. & $5.87(1.12)$ & $5.92(0.97)$ & $5.82(1.08)$ & -0.04 \\
\hline C.G. & $6.25(1.17)$ & $5.5(1.11)$ & $5.08(1.23)$ & -0.97 \\
\hline E. S. (Inter) & -0.33 & & 0.63 & \\
\hline Sc.I.M.A. & & & & E.S. (Intra) \\
\hline T.G. & $2.78(0.41)$ & $2.57(0.42)$ & $2.91(0.39)$ & .32 \\
\hline C.G. & $2.47(0.45)$ & $2.24(0.48)$ & $2.74(0.43)$ & 0.61 \\
\hline E. S. (Inter) & 0.72 & & 0.41 & \\
\hline
\end{tabular}


Table 3

Means and standard deviations of satisfaction variables

\begin{tabular}{|c|c|c|c|c|c|c|}
\hline Groups/Variables & T0 & $\mathrm{T} 2$ & $\mathrm{~T} 3$ & $\mathrm{~T} 4$ & $\mathrm{~T} 6$ & \\
\hline F.S. & & & & & & E.S. (Intra) \\
\hline T.G. & $4.38(0.44)$ & $4.34(0.36)$ & $4.19(0.45)$ & $4.35(0.37)$ & $4.3(0.46)$ & -.17 \\
\hline C.G. & $4.15(0.47)$ & $3.85(0.4)$ & $3.74(0.49)$ & $3.52(0.41)$ & $3.4(0.5)$ & -1.54 \\
\hline E.S. (Inter) & 0.51 & & & & 1.87 & \\
\hline Sc.S. & & & & & & E.S. (Intra) \\
\hline T.G. & $4.17(0.37)$ & $4.12(0.44)$ & $3.98(0.45)$ & $3.82(0.41)$ & $3.71(0.44)$ & -1.29 \\
\hline C.G. & $4.19(0.41)$ & $3.81(0.47)$ & $3.78(0.38)$ & $3.61(0.46)$ & $3.53(0.48)$ & -1.47 \\
\hline E.S. (Inter) & -0.05 & & & & .33 & \\
\hline T.S. & & & & & & E.S. (Intra) \\
\hline T.G. & $4.36(0.42)$ & $4.42(0.41)$ & $4.37(0.28)$ & $4.4(0.29)$ & $4.42(0.4)$ & .15 \\
\hline C.G. & $4.44(0.44)$ & $4.2(0.43)$ & $4.1(0.29)$ & $4.14(0.31)$ & $4.05(0.42)$ & -0.91 \\
\hline E. S. (Inter) & -0.19 & & & & 0.9 & \\
\hline
\end{tabular}


Table 4

Means and standard deviations of social validity items, and results of comparisons at a reference value.

\begin{tabular}{llllll}
\hline items & $\mathrm{M}$ & $\mathrm{SD}$ & reference value & $\mathrm{t}$ value & $\mathrm{p}$ value \\
\hline 1 & 3,58 & 0,86 & 3 & 2,44 & $<.05$ \\
2 & 4,33 & 0,47 & 3 & 10,19 & $<.001$ \\
3 & 3,01 & 1,08 & 3 & 0 & 1 \\
total & 3,64 & 0,53 & 3 & 3,98 & $<.01$ \\
\hline
\end{tabular}




\section{Figure Caption}

Figure 1. Temporal representation of the study 
Figure1

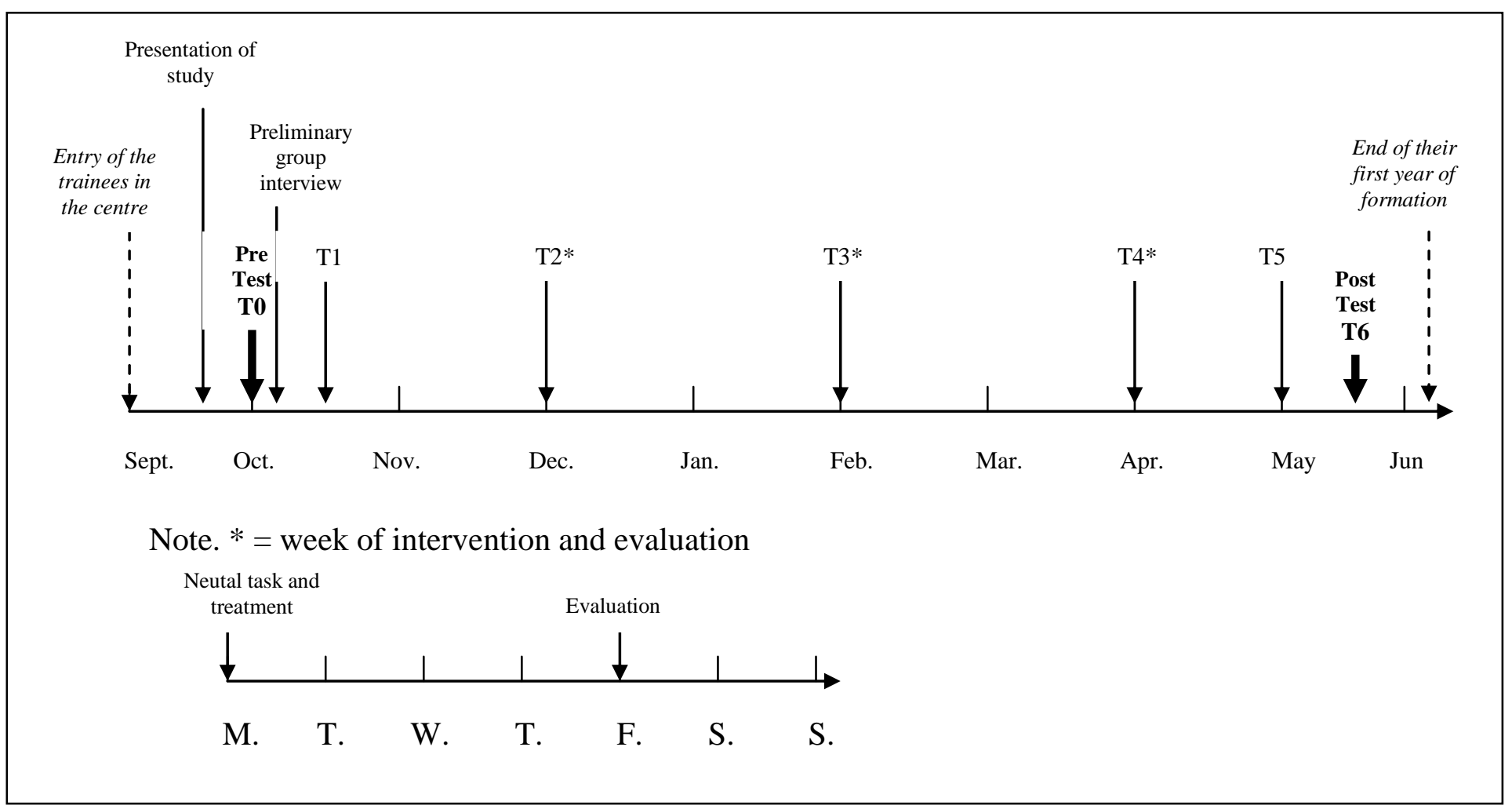

